\title{
Erratum to: Reliability of Postmortem Fentanyl Concentrations in Determining the Cause of Death
}

\author{
James R. Gill • Peter T. Lin • Lewis Nelson
}

Published online: 12 June 2015

(C) American College of Medical Toxicology 2015

Erratum to: Journal of Medical Toxicology

DOI 10.1007/s13181-012-0253-z

In Table 4 that appears in this article, data from the Martin article [12 11, 2.7-33)] should be in the "Natural, incidental use" column, not the "Intoxication, mean" column.

The online version of the original article can be found at http://dx.doi.org/ 10.1007/s13181-012-0253-z.

J. R. Gill $(\bowtie) \cdot$ P. T. Lin

New York City Office of Chief Medical Examiner and Department of

Forensic Medicine, New York University School of Medicine,

520 First Avenue, New York, NY 10016, USA

e-mail: jgill@ocme.nyc.gov

L. Nelson

Department of Emergency Medicine,

New York University School of Medicine,

New York, NY, USA 